\title{
artigos
}

DOI: 10.11606/issn.2318-8855.v3i3p171-194

\section{E os Pomos eram de Ouro: A importância da Citricultura de Nova Iguaçu para a economia fluminense e brasileira nas décadas de 1920 à de 1940}

\section{Ricardo Luiz Souza*}

Resumo: O presente trabalho possui como objetivos principais, esmiuçar a evolução da Citricultura no país e o seu grande desenvolvimento no município fluminense de Nova Iguaçu, no período compreendido entre as décadas de 1920 e 1940 do século XX. Não obstante, será também analisado nesse trabalho, como a laranja desenvolveu-se como uma alternativa de diversificação econômica, com o intuito de suprimir a grande dependência das exportações do café e como tal produto irá encontrar as condições para se desenvolver em Nova Iguaçu. Assim, discutiremos os incentivos, deliberações e políticas estatais para a laranja ser comercializada com a devida qualidade e pujança, com a adoção dos Packing Houses, entre outras medidas, além é claro, como o boom da produção e exportação de laranjas trará recursos financeiros para o Estado Brasileiro e Fluminense.

Palavras-Chave: Citricultura; Laranjas; Nova Iguaçu; Packing House.

\section{Introdução}

O presente trabalho possui por premissas principais resgatar e articular o período áureo da citricultura iguaçuana, compreendida entre as décadas de 1920 e 1940 do século passado. É um dos deveres da pesquisa histórica e da nova percepção e abordagem desta esmiuçar processos que parecem ser distantes e poucos tratados pela historiografia tradicional econômica, mas que tiveram total importância para o desenvolvimento de regiões, comunidades e cidades.

Essa cultura teve importante participação nos cofres fluminenses, principalmente a partir do Governo de Nilo Peçanha, que incentivou a diversificação da economia rural do

\footnotetext{
Graduado em História pela Universidade Federal Rural do Rio de Janeiro (UFRRJ). Contato: ricardoluisouza@gmail.com ou ricardo.souza@edu.ifsuldeminas.muz.br.
} 


\title{
artigos $\mid e$
}

Ricardo Luiz Souza

estado do Rio de Janeiro (PEREIRA, 1977, p.122). Pensar a economia brasileira num panorama que só desenhe São Paulo e a cultura da Rubiácea do Café, nos primeiros decênios do século XX, como principal fonte de divisas para a população e para as receitas públicas, é cair numa análise macroeconômica um tanto inocente. Alguns produtos conseguiram grande vulto e capital para a economia de nosso país, que tem dimensões continentais. Esse produto teve um vulto importantíssimo nos cofres fluminenses e consequentemente na economia do município de Nova Iguaçu. Nilo Peçanha, então presidente do Estado do Rio de Janeiro no período de 1903 a 1906, é figura importante nesse processo de diversificação da produção regional. Diversas eram as estratégias e nuances desse político no processo de mudança econômica que o Estado do Rio de Janeiro deveria passar para sair da crise:

\begin{abstract}
A administração Nilista seria marcada por um severo programa de saneamento das finanças públicas que visava a reduzir os gastos do estado e a ampliar a receita através de modificações no sistema tributário, e ainda pela implementação de um conjunto de medidas destinadas a incentivar a produção. Mesmo sem abandonar a cafeicultura e a lavoura açucareira, Nilo via na diversificação da agricultura a principal saída para a crise da economia fluminense. Tal convicção vinha reforçar a visão agrarista, então em voga, que exaltava a agricultura como a atividade básica da nação, apontando como evidência lógica dessa afirmação a dependência das cidades em relação ao campo. Com isso foi também descartada qualquer intenção oficial de criar incentivos para atividades industriais. (FERREIRA, 1994, p. 38)
\end{abstract}

Nesse ínterim, o Jornal Diário Carioca de 1928 destaca, com relevante ênfase, a importância do referido político na diversificação da produção agrícola do Estado:

As laranjas embarcadas no porto do Rio de Janeiro provém em sua quase totalidade do município fluminense de Nova Iguaçu, e o desenvolvimento ali, desta cultura, deve-se a ação administrativa de Nilo Peçanha, então presidente do Estado, no combate que sustentou contra a monocultura e nos estímulos que despertou as iniciativas particulares para o aproveitamento da terra de acordo com as possibilidades criadoras (Diário Carioca (RJ). Quinta feira, 19 de junho de 1928, p. 08).

Na virada do século XIX para o XX, o Estado do Rio de Janeiro já não era o líder na produção nacional de café, perdendo tal posto para o Estado de São Paulo (MELO, 2002, pp. 215-234). Consequentemente, o governo provincial do Estado do Rio de Janeiro começa a diversificar e a articular novas formas de angariar fundos para sua economia. Nisso, a laranja 


\section{artigos $\mid e$}

E os Pomos eram de Ouro: A importância da Citricultura de Nova Iguaçu para a economia fluminense e brasileira nas décadas de 1920 à de 1940

entra como um produto condizente com essa nova realidade, pois essa cultura se mostrara em franco crescimento e ainda demandava grande volume de mão de obra em suas fases de implementação, condução da lavoura, colheita e distribuição do produto final. Esses fatores dinamizavam a economia regional.

Nesse ínterim, refletir acerca da história econômica do Brasil, destacando somente ou exaustivamente a partir de uma concepção da produção e comércio do café, ou de outros produtos agrícolas com grande acervo historiográfico - algodão, borracha e cana-de-açúcar acaba encobrindo o suor e o esforço que muitos homens e mulheres que empreenderam em outras culturas. A laranja cultivada nas lavouras iguaçuanas é uma destas. Afinal, como um produto que teve grande consumo e produção no Brasil, se expandindo a uma velocidade estrondosa, pode ser tão pouco lembrado pela história econômica que investiga a primeira metade do século XX? Não obstante, um dos objetivos desse trabalho é justamente esmiuçar tal paradigma da ausência (ou quase ausência) desse produto na nossa história econômica e os desdobramentos que a segunda guerra mundial trouxe para tal produto.

A laranja definitivamente entrou na lista de consumo das famílias, no Brasil e no exterior, exigindo maior espaço no campo. A citricultura conquista a cidade de Nova Iguaçu, onde todas as características profícuas para o estabelecimento da laranja se encontravam. Essa cultura encontrou nas terras de Nova Iguaçu muitas características desejáveis para seu desenvolvimento em larga escala comercial. O solo com características próprias para o cultivo dos Citros, com textura mais arenosa do que argilosa, o relevo plano facilitando o trabalho nos tratos culturais e na colheita, além de propiciar menor erosão de matéria orgânica, temperaturas agradáveis para as laranjeiras produzirem seus açúcares da energia solar em quantidades excelentes, e um índice pluviométrico que colaborava para o bom enchimento dos frutos, trazendo uma coloração, sabor e aroma inigualáveis. Essas características dispostas contaram muito para o sucesso de tal empreendimento, tornando a fruta de grande aceitação no mercado. 


\section{$\operatorname{artigos} \mid e$}

Ricardo Luiz Souza

\section{Eis que surge uma nova atividade econômica}

O café, no decorrer dos anos da Primeira República, começa a passar por diversas crises de superprodução e dificuldades de exportação. Foram criadas políticas próprias para o café, como a defesa permanente, onde o produto era subsidiado e estocado para vendas futuras (FAUSTO, 1989, p.380). Esse sistema de proteção fez com que os plantios se alastrassem de uma forma nunca antes vista, criando superproduções que eram muito maiores que o consumo mundial da bebida. O Brasil adquiriu empréstimos no exterior, com o objetivo de comprar o excedente da produção, tática econômica essa que desestabilizava cada vez mais a economia, criando uma atmosfera de crise que se perpetuaria durante os anos 1920 (e principalmente com a quebra da Bolsa de Nova York em Outubro de 1929) e seria fator preponderante entre a ruptura das alianças oligárquicas ${ }^{1}$.

É no meio desse clima de mudanças e diversificações da produção rural que a laranja e outras frutas, como o abacaxi e a banana, vão se consolidar na pauta de novos produtos para os mercados internacionais e nacionais. Parafraseando um Presidente do Brasil em 1930: “A laranja salvará o Café" ${ }^{2}$.

Na Primeira República, eram intensos os debates acerca dos rumos da economia nacional. A extrema dependência do café como principal formador de divisas e a sua quase totalidade da produção concentrada no território do Estado de São Paulo, causava mal-estar político entre as demais unidades da Federação (FERREIRA; PINTO, 2003, p. 5). Esse processo foi uma das principais causas da cisão intra-oligárquica dos principais atores políticos da Primeira Republica: Minas Gerais e São Paulo. Assim, os debates em torno da diversificação econômica nacional expressavam em grande parte, preocupações de vários setores da sociedade brasileira com os rumos da nação. Nesse ínterim, outra grande disputa política nos últimos anos da Primeira República e nos primeiros momentos do governo provisório pós-

\footnotetext{
${ }^{1}$ Segundo Sônia Regina de Mendonça, a década de 1920 foi de grande efervescência política, com pressões de grupos que eram negligenciados com o núcleo de poder das oligarquias dos Grandes Estados (São Paulo, Minas Gerais, Rio Grande do Sul), além do aumento do custo de vida nas principais cidades. Ver: MENDONÇA, 1987; LINHARES, 1990, p. 322.

${ }^{2} \mathrm{O}$ autor que cita a frase em questão não define o Presidente do período compreendido entre a década de 1930 que proferiu tal declaração (PRADO JÚNIOR, 2004, p. 292).
} 


\section{artigos | e}

\section{E os Pomos eram de Ouro: A importância da Citricultura de Nova Iguaçu para} a economia fluminense e brasileira nas décadas de 1920 à de 1940

revolução de 1930 foi a indecisão sobre os rumos econômicos que a nação deveria seguir. Uma corrente defendia veementemente a industrialização do país, com o intuito de superar o atraso social e econômico ligados ao campo e à inanição que este causava nas populações. Já do outro lado, persistia a corrente que pugnava a vocação agrícola do Brasil, baseada nos campos e pastoreios, sendo o alicerce "moral" da sociedade. Nisso, a "chamada vocação agrícola do país", ganha ainda mais força com o auge das exportações de café entre 1910 e 1925 e o relativo sucesso que a rubiácea alcançou nos preços internacionais (OLIVEIRA, 1989, p. 187). A corrente da vocação agrícola aceitara que era preciso modernizar-se, mas sem abandonar o destino econômico do país, ou seja, a agricultura de exportação.

Seguindo esse aparente aspecto da vocação agrícola do país, Sônia Regina de Mendonça descreve o fato de que são criados mecanismos burocráticos nos setores administrativos da Primeira República, com o intuito de torná-la mais organizada e burocratizada, além de poder atender às diferentes classes produtoras, detentoras dos mais diferentes produtos de exportação.

Racionalizar a produção, tornando-a mais eficiente, esta era a meta dos ruralistas em questão. Produzir mais, com menores custos, seria o lema dos quais se propunham a atualizar a vocação eminentemente agrícola do país, [...] a "modernização" das lavouras pela mecanização, e a diversificação dos cultivos, mediante a adoção de métodos intensivos de plantio, seleção e beneficiamento das espécies (MENDONÇA, 2003, p.177).

Durante a Primeira República, há o surgimento da SNA (Sociedade Nacional de Agricultura), polo antagônico à burguesia cafeeira paulista, polo este hegemônico nos rumos da economia nacional. Os membros da SNA, em suas reuniões e propostas, procuravam discutir novas formas de desenvolvimento para o Brasil, com a paulatina busca por uma maior diversificação da produção nacional agrícola. Grande parte dos membros da SNA era de origem fluminense e teriam grande importância para o processo de diversificação e burocratização agrícola que irá ocorrer ${ }^{3}$.

\footnotetext{
${ }^{3}$ Amália Dias descreve em sua pesquisa o aumento significativo do número de membros da SNA, que passou de 4.000 membros em 1911 para 8.000 em 1929. Ver: DIAS, 2012, p. 61.
} 


\section{artigos $\mid e$}

Ricardo Luiz Souza

Nesse ínterim, o Brasil, na divisão internacional do trabalho, se mostraria como uma terra condizente para os mercados com o objetivo de produzir mercadorias primárias para a realização dos anseios externos. Essa demanda aumenta com a divisão internacional do trabalho e da produção de mercadorias manufaturadas e matérias-primas, fazendo que certas regiões, como já salientado no texto, tornem-se especialistas em produção de diferente gênero agrícola, mineral ou animal. Não obstante, os países que largaram na frente na corrida industrial financiaram a propagação em diversas partes do mundo da produção de certos gêneros de primeira necessidade de que sua indústria, economia e população necessitam. Nesse ínterim, estes países investem em alguma parte, na produção e compra de gêneros primários e agroexportadores. Em troca, exportam capitais, tecnologia e maquinário para as regiões onde esses produtos primários são os principais esteios da economia. A economia agroexportadora fica sempre a mercê das flutuações das cotações do mercado internacional, além de carecer cumprir sempre com seu papel de arcar com os investimentos perpetrados pelos meios externos.

Assim, a laranja entra como um produto perfeito para diversificar a produção nacional de produtos agricultáveis para a venda no exterior e para a alimentação da crescente população brasileira. A utilização do citros como alternativa ao café trará grandes benefícios e desenvolvimento para algumas regiões do país, principalmente, no caso desse estudo, do município de Nova Iguaçu. Interessante é perceber como a laranja no começo do século, na capital da República, tinha conotação pejorativa (HASSE, 1987, p.51). O comércio da laranja na cidade do Rio de Janeiro era feita na sua grande predominância por ambulantes, "biscateiros" e feirantes sempre dispostos a passar a perna no próximo. Não obstante, “Laranjeiro” passou a ser sinônimo de velhaco, malando e vigarista. Décadas mais tarde, com o alvorecer dos negócios relacionados à citricultura, a figura do laranjeiro seria sinônimo de grande mercador de frutas. 


\section{artigos $\mid e$}

\section{E os Pomos eram de Ouro: A importância da Citricultura de Nova Iguaçu para} a economia fluminense e brasileira nas décadas de 1920 à de 1940

\section{Os laranjais iguaçuanos.}

"Plante laranjas". Essa era uma frase ecoada por muitos cantos durante a fase áurea da cultura em Nova Iguaçu. Desde políticos das mais diferentes classes, passando por produtores, exportadores e agrônomos, tal frase tinha uma mensagem clara. "As terras do município de Nova Iguaçu foram feitas para essa cultura." Tal afirmação pode ser evidenciada na descrição do agrônomo Eduardo de Sampaio, funcionário do Ministério da Agricultura, no ano de 1932:

Pelas suas excepcionais propriedades de solo e condições de clima, é aquela zona o paraíso dos frutos cítricos e fatalmente destinada a abastecer os grandes mercados consumidores (AGRICULTURA, 1932, p. 58) ${ }^{4}$.

Não se sabe ao certo quando a laranja surgiu no território de Nova Iguaçu. Segundo Waldick Pereira, alguns homens importantes no período áureo dos laranjais, como Sebastião Herculano de Matos, presidente por diversos anos da Associação Dos Fruticultores do Município, veem o início no ano de 1883, quando começam algumas pontuais vendas para o exterior (PEREIRA, 1977, P.122).

Uma característica bem interessante da citricultura que surge nesse momento é o interesse e o uso de informativos agrícolas feitos por empresas relacionadas ao ciclo produtor da laranja. Estas empresas disponibilizavam nesses encartes informações de como proceder no melhor trato à lavoura. Continham conhecimentos que iam desde a melhor escolha das mudas e enxertos até a fase de plantio com os espaçamentos mais condizentes para o tamanho do terreno do produtor, método esse empregado para que o pomicultor aproveitasse melhor sua terra, com um número maior de plantas por hectare ou alqueire ${ }^{5}$.

\footnotetext{
${ }^{4}$ Com o intuito de alavancar a produção citrícola no país (além de outras frutas, como abacaxi e banana), será criada uma nova pasta dentro do Ministério da Agricultura que e terá como objetivo orientar com pesquisas e trabalhos de campo a melhor condução da pomicultura, tanto em seus aspectos gustativos, estéticos, exportadores e também, pesquisas para uma boa condução na lavoura.

${ }^{5} \mathrm{O}$ informativo "Conselhos práticos para a Cultura de Laranjeiras", com 20.000 tiragens e escrito por Francisco França no ano de 1936, trazia inúmeras informações acerca de como proceder corretamente com a cultura da laranja. Indicava as melhores épocas do ano para as capinas, enxertos, adubações e correções de solo, além de indicar produtos fitossanitários para o citros. Um dado importante que esse informativo trás, é a melhor otimização da área com o plantio das laranjeiras em espaçamentos menores, para uma maior produção por área.
} 


\section{$\operatorname{artigos} \mid e$}

Ricardo Luiz Souza

Muitas empresas multinacionais do ramo químico, como a alemã Bayer e a francesa Rhodia se interessavam e desenvolveram produtos para os tratos culturais nas lavouras ocupadas pela laranja. Operações como a pós-florada ou a assepsia das lavouras eram vistas pelos departamentos comerciais e técnicos de tais empresas como importantes no faturamento. Alguns produtos como o Solbar, fungicida para aplicação antes e depois da florada do citros, tiveram ampla divulgação na imprensa e eram usados frequentemente pelos citricultores. Com informativos técnicos, a Bayer ${ }^{6}$ divulgava seus produtos e auxiliava os produtores com o apoio de uma equipe técnica da empresa, todos os cuidados técnicos para o cultivo da citricultura na região de Nova Iguaçu.

A laranja entra em um processo bastante interessante que estava acontecendo no campo brasileiro: a modernização agrícola. Tal processo não só residia no fato de se produzir no campo só resultados econômicos, mais que tais resultados trouxessem também implicações relacionadas a um dinâmico desenvolvimento social e tecnológico do homem do campo. Nesse ínterim, são destacadas a colocação de técnicos e agrônomos e utilização em larga escala da mecanização para esse fim, visto que estes elementos seriam a "virada" do processo modernizador da agricultura (MENDONÇA, 2002, p.231).

Hasse assinala que na maioria dos casos, os primeiros cultivos de citros no final do século XIX, não era no Rio de Janeiro e em seus arredores (em especial Nova Iguaçu) uma atividade agrícola com cunho comercial. Nas terras das antigas fazendas, um sítio valia mais se em seu interior se cultivasse um pomar e isso demonstra o pequeno zelo para com a cultura em seus primórdios, quando os grandes proprietários de terras ainda não viam a riqueza que poderia provir.

No final do século XIX, os pomares iguaçuanos eram infestados por uma doença chamada de fumagina ou "Morphea das laranjeiras", doença esta provocada pela falta de

Esse informativo aconselha o plantio com espaçamentos de $6 \mathrm{~m}^{2}$ ao invés de $7 \mathrm{~m}^{2}$, o que daria uma população de plantas na ordem de 1344 pés contra 987 pés respectivamente por alqueire. Ver: França (1936, p.04)

${ }^{6}$ Muitos produtos para a agricultura nacional eram produzidos por essa empresa alemã. Em 1958, a Bayer monta suas instalações em território iguaçuano, no Distrito de Belford Roxo. Em 1990, Belford Roxo se desmembra de Nova Iguaçu, ficando com a Sede da fábrica em seu território. Ver: Pohl; Wilcke; Dupré (2008, p. 47). 


\section{$\operatorname{artigos} \mid e$}

\section{E os Pomos eram de Ouro: A importância da Citricultura de Nova Iguaçu para}

a economia fluminense e brasileira nas décadas de 1920 à de 1940

saneamento nos campos de cultivo e nos grandes alagadiços que a Baixada possuía antes das grandes obras de saneamento e controle de alagadiços. Tal moléstia foi controlada com a ajuda de agrônomos do IAC (Instituto Agronômico de Campinas). Apesar dos problemas sanitários, “a citricultura fluminense foi, durante muitas décadas, uma referência para todo o Brasil". Seriam nas terras iguaçuanas que surgiriam duas das mais importantes variedades de cítricos para a economia: a laranja pera e a mexerica do Rio (HASSE, 1987, p.47).

O projeto de saneamento das terras com potencial agricultável na Baixada Fluminense tem início no ano de 1909, a mando do Governador Nilo Peçanha. De acordo com os registros do Diretório de Fruticultura, de 1932, uma equipe de engenheiros é contratada para levantar as plantas da Baixada. Em seguida segundo esse mesmo relatório, 42.000 hectares de terras são saneados e drenados, acabando com as grandes fontes de criadores de mosquitos e outras intempéries que há anos castigavam a população de tais localidades.

Numa primeira fase, os pomares eram plantados nas zonas dos morros, nos contrafortes e mesmo nas encostas da Serra de Madureira, porém, com a valorização do produto crescente, o plantio também se alastrou pelos baixos montes e planícies que já se encontravam drenadas pelas grandes obras de saneamento, espalhando-se em seguida assim por vastos rincões de terra do município. Essa mudança de eixo no plantio e condução dos pomares levou a uma melhora no transporte do produto pelos caminhões e pelos vagões da via férrea.

A laranja mais plantada e que teve sua origem em Nova Iguaçu era a da variedade pera. Esses frutos se caracterizavam por possuir alta resistência, o que era uma vantagem bastante interessante se levarmos em conta os longos e desgastantes processos de colheita, beneficiamento e exportação. Essa variedade também era considerada os "pomos de ouro" das lavouras pelos produtores devido ao seu tamanho, casca fina e ótimo sabor. Uma nota do jornal carioca Correio da manhã demonstra a grande aceitação da laranja pera no mercado britânico:

Muito embora as laranjas "selectas" de São Paulo cessaram de chegar em meados de Agosto, essa fruta brasileira continuará sendo vendida na Inglaterra até os fins deste mês, devido aos embarques da laranja pera do Rio 


\section{$\operatorname{artigos} \mid e$}

Ricardo Luiz Souza

de Janeiro, que começou a aparecer no mercado. Acredita o cônsul do Brasil que elas conseguirão altos preços devido ao seu tamanho, a finura da pele e ao sabor admirável do suco, aliado ao aroma suave que se desprende das frutas brasileiras (Correio da Manhã (RJ), 17 de maio de 1930).

Examinando tal afirmação nessa fonte jornalística, podemos perceber o quanto essa variedade de laranja era atrativa nas mesas dos súditos da rainha, pois os ingleses preferiam laranjas com tamanho menor, por possuírem um custo unitário baixo e serem mais fáceis para a partilha nas famílias com menor renda (HASSE, 1987, p. 66). A qualidade para ganhar esse nicho de mercado exigia cuidados que iam desde a produção das sementes e mudas, plantio, colheita e transporte dos frutos. Todas essas premissas influenciavam na qualidade do produto final, e essa era uma preocupação tanto dos governos em suas demais instâncias, tanto dos exportadores que firmavam compromissos como os mercados internacionais.
A laranja foi parte de um movimento de diversificação na pauta da exportação brasileira na década de 30. Nos dez anos entre 1929 e 1939, a participação do café na exportação caiu de $70 \%$ para $40 \%$ aproximadamente. Em 1939, apenas nove produtos representavam $77,6 \%$ da receita cambial brasileira. A laranja era um dos dez mais na exportação (HASSE, 1987, p.66).

Nos anos 1920, o Brasil já despontava no cenário econômico mundial como o $5^{\circ}$ maior produtor mundial de Citros, ficando abaixo de verdadeiras potências mundiais, com produção há algum tempo consolidada como a Espanha, Estados Unidos da América (com a produção concentrada no Estado da Flórida), Japão e Itália. Mas, nenhum desses países possuía terras para expansão como o Brasil, além de clima propício, mercado interno e mão de obra para o pleno desenvolvimento da citricultura.

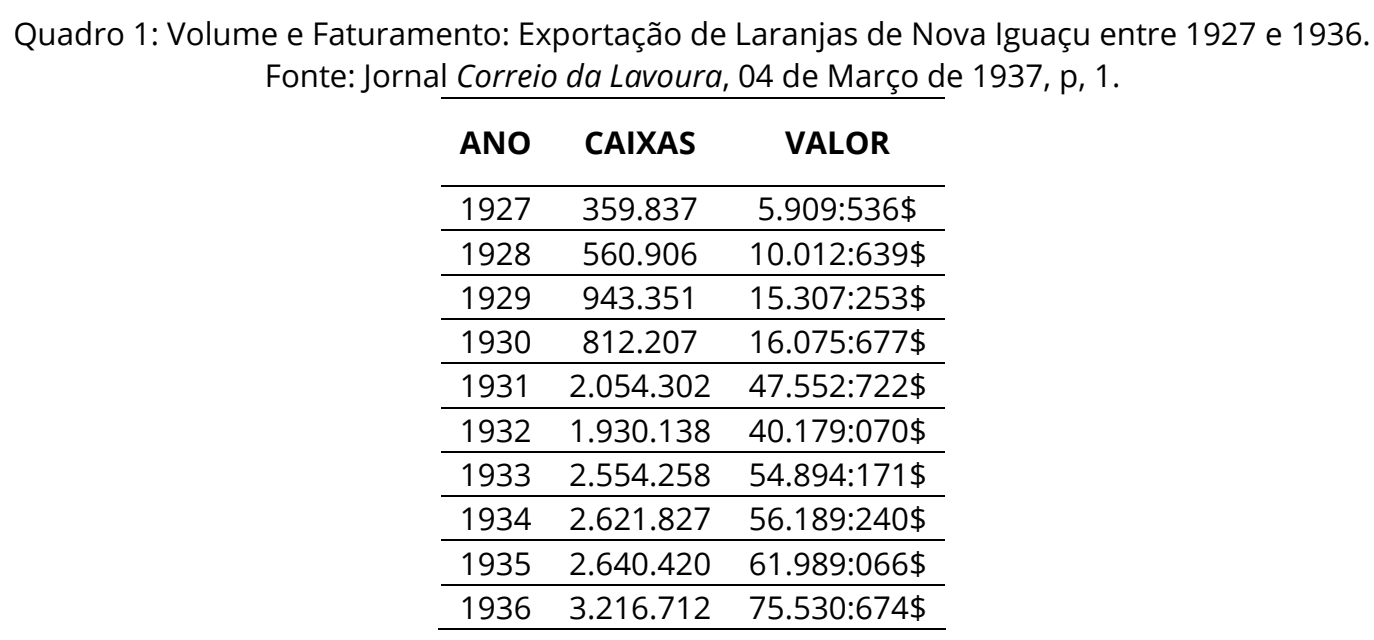




\section{artigos | e}

\section{E os Pomos eram de Ouro: A importância da Citricultura de Nova Iguaçu para} a economia fluminense e brasileira nas décadas de 1920 à de 1940

Verifica-se a partir da tabela do jornal Correio da Lavoura, exposta acima, um considerável aumento de divisas e de produção citrícola entre os anos de 1927 e 1936 . O valor das exportações cresce num ritmo acelerado no decênio 1927-1936 com aproximadamente $893 \%$ de aumento no volume de caixas exportadas. Já a rentabilidade dessa exportação crescente nesse mesmo período cresce de forma ainda mais acachapante, com aproximadamente 1.278\% de aumento, no período de 1927 a 1936.

No relatório, expedido pelo do Ministério da Agricultura no ano de 1938 ${ }^{7}$, a laranja figurava entre os dez principais produtos exportados pelo país no mercado internacional. Após o café e o cacau, a laranja vinha como o terceiro produto alimentício mais exportado. Como revela tal relatório, os maiores crescimentos a partir do ano de 1930 competem à laranja, que apresenta o extraordinário índice de aumento de 612\%, seguido pelas carnes em conserva, com 317\%; o cacau com 157\% e a banana com 144\%. No que tange aos preços verificados no período compreendido entre o ano de 1930 e 1939, a laranja alcança a formidável marca de crescimento em valor de $289 \%$.

Assim era a importância da laranja, conforme os anos iam passando a partir da década de 1930, a produção e o uso do solo para o cultivo da citricultura aumentariam de forma substancial em alguns territórios do Brasil, mais especificamente em Nova Iguaçu e Limeira, no Estado de São Paulo

Os grandes mercados importadores das laranjas produzidas em Nova Iguaçu eram em especial os países Europeus. O Ministério da Agricultura, no ano de 1932, através do seu Diretório de Fruticultura, faz um levantamento bastante especial sobre a citricultura do município de Nova Iguaçu e traz como paralelos seus principais mercados internacionais:

Não há dúvida que os melhores mercados para a exportação da laranja estão na Europa. A Inglaterra recebe um terço da Exportação total. A Alemanha vem em segundo lugar, como melhor cliente. Pela ordem de importância, seguemse a França, Noruega, Suécia, Hungria, Dinamarca, Irlanda e Romênia (AGRICULTURA, 1932, p. 30).

\footnotetext{
${ }^{7}$ Tal documento pode ser obtido virtualmente e é uma ótima fonte para o estudo econômico dos mais diversos produtos econômicos nacionais. Brasil, leis, decretos. Relatório do Ministério da Agricultura de 1938 , p.14. <<http://brazil.crl.edu/bsd/bsd/u2026/000025.html>>. Acessado em 02/02/2015 às 9h00.
} 


\section{artigos $\mid e$}

Ricardo Luiz Souza

Outro grande comércio para os frutos colhidos era o mercado interno (com o envio de frutos de menor qualidade). Nova Iguaçu pela sua proximidade de grandes centros consumidores como os Estados de Minas Gerais, São Paulo e Rio de Janeiro - os três com maiores contingentes populacionais - facilitava tal processo. De acordo com nota do jornal Diário Carioca, a Bacia do Prata, era no ano de 1927 um dos principais clientes dos laranjais de Nova Iguaçu.

Dia a dia avulta a exportação de frutos especialmente da laranja, que vae vencendo a má vontade das autoridades dos países consumidores graças ao capricho e zelo dos produtores no esforço de melhorar o produto.

E completa:

Sobre esse movimento de exportação tão auspicioso à economia nacional, ouvimos ontem, ligeiramente o encarregado da exportação de frutas brasileiras que manteve conosco interessante palestra. Disse-nos ele que durante o ano de 1927, foram embarcadas pelo porto do Rio de Janeiro 350,270 caixas de laranja num total de 70,054,00 frutos. Em decrescente embarcamos frutas para Buenos Aires, Londres, Itália, Hamburgo, Holanda, Montevidéo e Havre, e já conquistamos uma invejável posição nesses mercados (Diário Carioca (RJ), 19 de junho de 1928, p.07).

A partir de tal nota jornalística citada acima, podemos ver a importância dos mercados da bacia do Rio da Prata para a exportação de laranjas. Importância essa que seria minada a partir da década de 1930, com o maior direcionamento da exportação para a Europa.

Na mesma página desse periódico, o artigo ainda cita que "as laranjas embarcadas no porto do Rio de Janeiro provém em sua quase totalidade do município fluminense de Nova Iguaçu". Tamanha a importância da laranja para os cofres do Estado do Rio de Janeiro era o fato de que essa economia foi no ano de $1934^{8}$, a principal detentora de divisas para o Estado fluminense. Segundo Ferreira:

A nova política desenvolvida pelo Departamento Nacional do Café (DNC) de favorecer o escoamento de cafés finos atingiu frontalmente a Cafeicultura fluminense, que produzia cafés inferiores com restritas possibilidades de

\footnotetext{
${ }^{8} \mathrm{O}$ autor também destaca em seu artigo que o algodão, no Estado do Rio de Janeiro nos anos 1930, sofreu crescimento vultoso, mais nenhuma atividade agrícola apresentou aumento tão notável quanto o cultivo da laranja, que encontrou na Baixada Fluminense, clima, solo e relevo favoráveis à expansão da produção. Nova Iguaçu era, de longe, o maior produtor do estado (LAMARÃO, 2010).
} 


\section{artigos $\mid e$}

\section{E os Pomos eram de Ouro: A importância da Citricultura de Nova Iguaçu para} a economia fluminense e brasileira nas décadas de 1920 à de 1940

exportação. A partir de 1933, o café deixou de ser o principal produto da economia estadual e o maior contribuinte na arrecadação da renda, com $28 \%$,seguido pela laranja com $17,80 \%$ e pelo açúcar com 13,89\%. Em 1934, o principal item da pauta de arrecadação estadual era a laranja, ficando o café em segundo lugar (FERREIRA, 1994, p. 99).

O relatório do Ministério da Agricultura no ano de $1932^{9}$ enumera os principais concorrentes da Laranja de Nova Iguaçu na Europa. Os Estados Unidos são os maiores produtores mundiais, mas devido ao alto consumo per capita, consomem sua própria produção. A Espanha figura em 1932 como a maior exportadora, porém, sua época de colheita não entrava em choque com a safra e exportação Iguaçuana, que tinha o grosso de seus volumes realizada nos meses de agosto a dezembro, sendo essa característica climática e de ordem geográfica primordial para fazer os negócios prosperarem pelas bandas da Baixada Fluminense. Produzir com qualidade era então uma premissa procurada pelos exportadores e pelo Estado para vencer a forte concorrência internacional.

De acordo com Sônia Regina de Mendonça, a súbita crise de 1929 e a consequente queda nos preços de produtos agrícolas no consumo mundo afora, levou a mais estreita necessidade de se fazer cumprir os compromissos com as importações em geral, e tornava-se ainda mais vital e urgente o intervencionismo do Estado de modo a propiciar aos proprietários rurais melhores condições para a colocação doméstica de seus produtos. Ou seja, a diversificação da produção agrícola, deixaria de ser apenas uma alternativa para complexos agrários menos dinamizados, passando a ser instituída uma "questão nacional", materializada à sombra de déficits da Balança Comercial a serem minimizados no concerto de uma economia mundial em profunda recessão (MENDONÇA, 2013, p.31). Nos dizeres do Diretório de Fruticultura, os incentivos estatais eram primordiais para o sucesso da laranja em Nova Iguaçu, "Certamente a iniciativa particular jamais sem o auxílio oficial, inspirará confiança ao estrangeiro" (AGRICULTURA, 1932, p.58). Verifica-se a mão do Estado como o

\footnotetext{
${ }^{9}$ Nessa parte do relatório, é notória a preocupação das autoridades governamentais nacionais pela qualidade e sanidade das laranjas enviadas ao exterior. Nos dizeres dos técnicos, só a venda de um produto de ótima qualidade poderá vencer a grande concorrência externa (AGRICULTURA, 1932).
} 


\section{artigos $\mid e$}

Ricardo Luiz Souza

gerenciador e administrador da economia e o seu interesse em diversificar a produção agrícola.

Uma das principais e mais imediatas implicações do movimento revolucionário de 1930 foi a intervenção e o gerenciamento do Estado em alguns setores da esfera econômica. Essa mudança no papel, até então pouco desempenhado pelo Estado em relação à Primeira República, é também influenciada pela grande relação impactada pela crise econômica internacional, provocada pela crise de 1929. Essa crise, seguida de longa recessão mundial, afetou profundamente toda a esfera econômica brasileira. Para combater os efeitos da crise, o Estado assume, então, poderes inéditos na coordenação, planejamento, controle e incentivo a várias atividades econômicas, criando assim, diversos órgãos governamentais específicos para cada atividade econômica.

Sônia Regina de Mendonça ainda salienta que a atuação do Ministério da Agricultura no pós-1930 orientou-se pelo aprofundamento da diversificação agrícola do país, entendida quer no tradicional sentido do abastecimento interno de sua crescente população, quer no da ampliação da pauta de exportações brasileiras para os mais diversos mercados internacionais:

Inaugurava-se, também, no rearranjo do Estado restrito brasileiro no pós1930, a prática da criação de autarquias especializadas em ramos ou setores produtivos as quais, diretamente vinculadas ao Executivo, transformavam-se quer em instrumentos de absorção dos conflitos intraclasse dominante pela sociedade política, quer em veículos da nacionalização das decisões econômicas, superando o embate regionalismo versus centralização política (MENDONÇA, 2013, p. 63).

Nilo Peçanha, em sua gestão como então Governador do Estado do Rio de Janeiro, contribuiu para o desenvolvimento da citricultura no estado fluminense, sendo fundamental para o estabelecimento e sucesso da citricultura nos campos iguaçuanos. Seja tanto por incentivos como a redução das taxas aduaneiras ou isenção de impostos comerciais das remessas de caixas de laranjas. 


\section{artigos $\mid e$}

\section{E os Pomos eram de Ouro: A importância da Citricultura de Nova Iguaçu para} a economia fluminense e brasileira nas décadas de 1920 à de 1940

O governo provisório tratou logo de ser uma espécie de gerenciador da economia nacional ${ }^{10}$, estimulando a produção sistemática de certos produtos em detrimento de outros - o café ainda é o maior produto na pauta de exportações, como mais de 40\% de participação na pauta de exportações, recebendo ainda, muitos incentivos, mais a abertura de novas aéreas de cultivo não são incentivadas. Essa era uma tendência geral que se apresentava em diferentes matizes na América Latina como um todo. O Estado como "administrador da economia", gerenciando-a e coordenando a produção em seus mais variados setores. Essa foi uma diretriz muito em voga em toda América Latina:

Este fue también el período en que el Estado represento um creciente papel en la agricultura y en otros sectores de La economía. En toda América Latina, La intervención estatal por medio de organismos burocráticos y programas de extensión, ayudas y comercialización se convirtió em un rasgo ordinario de La economía agrária (OLIVEIRA; ROBERTS, 2005, p. 279).

\section{Os Packing Houses}

O sucesso alcançado com a exportação da laranja em Nova Iguaçu trouxe uma verdadeira revolução no modo de produção da fruta. Com a exportação em alta, e a conquista cada vez maior de mercados estrangeiros diversificados - e ao mesmo tempo, exigentes em fatores referentes à qualidade do fruto, tais como aspecto, coloração, aroma e sabor -, se tornaria necessário para se firmar o compromisso com tais mercados entregar uma fruta que seguisse um padrão de qualidade e que chegasse à mesa do consumidor final com atributos que intensificassem ainda mais a fama da "melhor laranja do mundo" (CARVALHO, 1999, p. 51). A resposta para essa encruzilhada foi à adoção dos "Packing Houses $^{\prime 11}$ (em português, casas de embalagem).

O Jornal do Brasil, em uma reportagem de janeiro 1929, destaca uma importante resolução do Ministério da Agricultura, a compra de equipamentos vindos dos Estados

\footnotetext{
10 Esse gerenciamento fazia parte do pacto feito entre o Governo Provisório e as diversas elites nacionais, principalmente feito pela burguesia industrial, pois este extrato social encontrava-se em processo intenso de ascensão econômica no cenário nacional (MENDONÇA, 1987).

${ }^{11}$ Nova Iguaçu apresenta um notável desenvolvimento no número de Packing Houses e, já em 1931, existiam cerca de 13 instalações desse tipo, excluindo-se o pertencente ao Ministério da Agricultura, e em apenas 4 anos, esse número sobe prodigiosamente para 24 instalações desse tipo.
} 


\section{artigos $\mid e$}

Ricardo Luiz Souza

Unidos da América e a construção dos primeiros Packing Houses, sendo dois locais contemplados: Limeira e Nova Iguaçu. Segundo tal hebdomadário, os agricultores de Nova Iguaçu mostraram-se bastante animados com tal notícia:

O Dr. Leva Castro, Ministro da agricultura, tendo em vista o desenvolvimento extraordinário, que está tomando a exportação de frutas, principalmente as laranjas, etc... já encomendou nos Estados Unidos duas completas instalações de "packing house" com capacidade para 2.400 caixas de laranja diárias, na importância de 318:832\$000, quantia essa que já foi posta a disposição do nosso cônsul geral de Nova York, por telegrama de 11 do corrente mês. Os agricultores de Nova Iguaçu, indo ao encontro do louvável ato do $\mathrm{Sr}^{\circ}$ ministro da agricultura, vão construir os edifícios para as instalações da sua "packing house" (Jornal do Brasil (RJ), 19 de janeiro de 1929, p.5).

A efeméride ${ }^{12}$ de Luiz Azeredo do dia 23 de junho de 1929 apresenta a informação de que o Presidente do Estado, o Dr. Manoel Duarte visitara Nova Iguaçu, acompanhado do Secretário Municipal da Agricultura e Obras Públicas, Dr. Rio Borges. Essas autoridades inspecionaram o local onde o Estado Fluminense pretendia construir, para a Associação dos Fruticultores, uma casa de embalagem de frutas (Packing House) para exportação.

Os Packing Houses eram barracões onde se estabelecia um interessante e importante processo da produção citrícola, o beneficiamento dos frutos. Operavam em média, cerca de cem pessoas, entre homens, mulheres e crianças, constituindo um importante mercado de trabalho para a cidade (SOUZA, 1992, p. 58). Nessas instalações, a laranja era processada e beneficiada, ato que começava desde a lavagem dos frutos (alguns frutos chegavam bastante sujos, devido ao manuseio da colheita e transporte), onde depois de lavados, eram secos pela ação de poderosos ventiladores. Após esses processos iniciais, a laranja era escovada por uma maquinaria apropriada e por fim, separadas, classificadas de acordo com seu aspecto, tamanho e qualidade, para assim serem embaladas e encaixotadas. Estas instalações na maioria das vezes também eram usadas como depósito para as caixas que ainda seriam embarcadas pelos caminhões ou pelos vagões do trem.

\footnotetext{
${ }^{12}$ Essas efemérides podem ser consultadas no CEDIM (Centro de Documentação e Memória da UFRR), campus Nova Iguaçu). Esse centro possui rico acervo histórico disponível em variadas fontes sobre a história de Nova Iguaçu e região. Efeméride do dia 23 de junho de 1929.
} 


\section{artigos | e}

\section{E os Pomos eram de Ouro: A importância da Citricultura de Nova Iguaçu para a economia fluminense e brasileira nas décadas de 1920 à de 1940}

Essas instalações seriam importantes no projeto de se organizar a produção, e assim, entregar para os mercados estrangeiros um produto nos mais altos padrões de qualidade. $\mathrm{O}$ relatório do agrônomo Eduardo de Sampaio ${ }^{13}$ salientava essa preocupação:

Por último, é importantíssimo, só se fazer a embalagem em entrepostos dotados de toda maquinaria moderna e aperfeiçoada que para esse fim existe, onde possa proceder à uma rigorosa seleção e beneficiamento de modo à que os frutos cheguem nos centros consumidores em estado de conservação e com aparência exigidos para sua boa cotação (AGRICULTURA, 1932, p. 60).

Antes dessas instalações, os frutos eram embalados em sacos de aniagem e caixas de cebola, o que significava muitas perdas na qualidade final do produto, pois os frutos poderiam sofrer esmagamentos, perdendo suas características gustativas. Além desse problema, poderiam sofrer fermentações indesejáveis e uma perda de aspecto estético. É importante o fato de que também os sacos e caixas de cebola não eram suficientes para atender toda a demanda dos exportadores. Essa demanda por caixas de madeira estimulou o desenvolvimento da indústria madeireira no norte do Paraná (PEREIRA, 1977, p.140), onde a produção de tábuas de pinho branco para a confecção de caixas encontrou um grande mercado: as laranjas iguaçuanas.

Os Packing Houses trouxeram uma nova modalidade de trabalho para a cidade. No eixo econômico trazido pela citricultura, podemos perceber o aparecimento de uma frente industrial que operava no funcionamento de tais instalações. O mercado de trabalho a partir da inauguração dos Packing Houses expandia-se com novas categorias de trabalhadores, nas mais variadas funções adjacentes, que iam deste a produção, mecânicos de manutenção das máquinas, lavadoras, encaixotadores, secretárias, corretores, caminhoneiros, etc. (PEREIRA, 1977, p.141). E essas novas funções trabalhistas vão se diferenciar das atividades referentes aos tratos culturais dos laranjais, como as capinas, adubações e podas, criando assim, um novo mercado de trabalho onde a produção agora obedece a uma dinâmica industrial, variando em sofisticação e especialização. Nessa nova dinâmica de produção, vários trabalhadores vão se instalando em funções como o transporte das frutas dos pomares até

\footnotetext{
${ }^{13}$ O Agrônomo Eduardo de Sampaio era encarregado do Diretório de Fruticultura, e atuava em Nova Iguaçu.
} 


\section{artigos | e}

Ricardo Luiz Souza

os embarques, na fabricação de caixas de madeira em barracões próprios para esse fim, na limpeza e embalagem dos frutos e no tratamento e acondicionamento das laranjas entre outros serviços.

Nova Iguaçu apresentava, assim, um notável desenvolvimento no número de Packing Houses. Já em 1931, existiam 13 instalações desse tipo, excluindo-se o pertencente ao Ministério da Agricultura, e em apenas 4 anos, esse número sobe prodigiosamente para 24 instalações desse tipo. Esse crescimento vertiginoso levou ao enriquecimento e prestígio de muitos homens, como exemplo o italiano Francisco Baroni, grande exportador de frutas e detentor de três Packing Houses, sendo um localizado no bairro carioca de Campo Grande ${ }^{14}$ e dois no município de Nova Iguaçu. É importante notarmos as trocas de conhecimento técnico e maquinaria em conjunto com o intercâmbio dos agrônomos americanos da região californiana e os técnicos nacionais que atuaram na região de Nova Iguaçu, pareciam ser intensos, motivados pela crescente influencia que o capital financeiro Norte Americano (DEAN, 1989, p.256) já trazia para a economia brasileira pós-primeira Guerra Mundial.

O cooperativismo era visto como grande alternativa para as crises que os produtores e toda a cadeia produtiva da laranja passavam de tempos em tempos. Como todo produto agrícola de caráter exportador, os preços internacionais da laranja sofriam oscilações frequentes, tanto pelos ritmos de consumo que eram variáveis mundo afora, tanto pelo crescimento de potenciais concorrentes como a Espanha e os países da Europa mediterrânica. Nisso, o cooperativismo era uma grande ferramenta para o sucesso da citricultura, pois poderia oferecer aos produtores preços melhores de fretes, insumos para a lavoura em geral e crédito. A principal cooperativa do período áureo da laranja em Nova Iguaçu se localizava no Distrito de Austin. De acordo com as notas dos jornais Diário Carioca e A Batalha, ambos do então Distrito Federal, cooperação entre os produtores poderia alavancar a citricultura com segurança e pujança:

\footnotetext{
${ }^{14}$ É bem provável que os Packing Houses de Francisco Baroni tenham beneficiado as laranjas produzidas pelos produtores da região de Campo Grande, na Zona Oeste da cidade do Rio de Janeiro. No artigo de Pedro Fonseca Leal, são analisadas as atividades agrícolas realizadas por produtores nessa região e a Laranja na década de 1930 foi uma importante fonte de renda para estes (LEAL, 2010, p. 71).
} 


\section{artigos}

\section{E os Pomos eram de Ouro: A importância da Citricultura de Nova Iguaçu para a economia fluminense e brasileira nas décadas de 1920 à de 1940}

Com a inauguração do "Packing House" de Nova Iguaçu, podê-se afirmar que a citricultura fluminense entrou no plano de organização graças a ação do governo. Foi uma vitória do cooperativismo e isto porque somente depois que os grandes e pequenos citricultores se organizaram em cooperativas, tornouse possível a sua emancipação (A Batalha (RJ), 30 de agosto de 1939, p.04).

De acordo com os referidos jornais, ainda seriam construídas mais duas cooperativas: uma em Austin e outra em Queimados. Essas cooperativas de agricultores tinham como premissa principal solucionar sistematicamente as crises agudas sofridas pelos citricultores iguaçuanos, principalmente no que concerne à questão de preços e à qualidade do produto final. A cooperação entre os produtores era vista como uma ferramenta para a citricultura crescer forte e com objetivos pautados no desenvolvimento. Segundo os jornais apresentados, essa instalação procurava, também, ser uma garantira da qualidade do produto final também ao mercado interno:

O grande "packing-house" da Cooperativa dos Citricultores de Nova Iguaçu destina-se ao beneficiamento e a embalagem de frutas, bem como à sua venda para os mercados externo e interno. Ao consumidor nacional as frutas são vendidas em péssimas condições e embalagem precária. A aludida Cooperativa está aparelhada para colocar no mercado interno laranjas seccionadas em ótimas condições de embalagem, tendo ainda a capacidade para beneficiar diariamente perto de cinco mil caixas de laranjas ( $A$ Batalha (RJ), 30 de agosto de 1939, p.04).

A nota do Jornal acima elucida de forma bem clara o direcionamento dos melhores frutos para a exportação, deixando para o consumidor interno os com menor padrão de qualidade. No processo de seleção que acontecia na maquinaria e nas mãos dos “operários da laranja", os melhores mercados sempre teriam a chance de desfrutar dos melhores produtos, e essa é uma diretriz que sempre será exercida pelo mercado. Tal cooperativa visava, contudo, quebrar esse processo, algo que seria bem difícil em se tratando do direcionamento da exportação, pois é um processo que acontece até os dias de hoje, com os mais diversos produtos agrícolas. 


\section{artigos $\mid e$}

Ricardo Luiz Souza

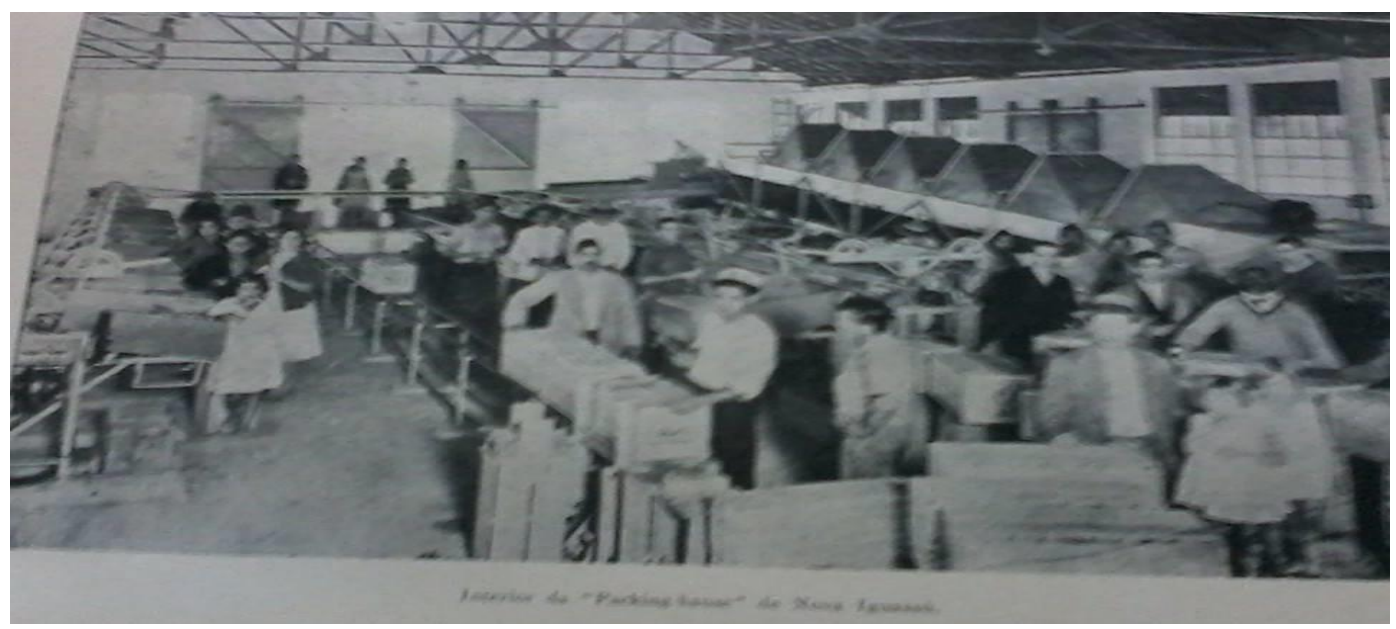

Imagem 1: Fotografia do interior de um Packing House em Nova Iguaçu. Fonte: Agricultura (1932, p. 60).

A partir da imagem acima, podemos perceber o grande número de trabalhadores e a maquinaria empregados nos Packing Houses, nas mais diversificadas funções, tais como: limpeza dos frutos, acondicionamento dos frutos, seleção das melhores frutas, armazenamento nas caixas de madeira entre outras. Diferente dos trabalhos nas lavouras de laranjais, a rotina de trabalho nos barracões seguia assim uma lógica industrial. Essas instalações seguiam assim a vertente da modernização da agricultura, com os objetivos de torná-la mais produtiva e qualitativa.

\section{Conclusão}

Nossa pesquisa mostrou como os anos de 1930 caracterizaram-se por um período de intenso movimento de intervenção estatal na economia. Buscava-se diversificar a produção nacional de bens agrícolas, para atenuar às profundas crises oriundas de um mundo em recessão, decorrente da grande queda da Bolsa de 1929 e da queda abrupta do café, de longe, o principal produto de exportação brasileiro. Esta não foi a primeira intervenção na economia local. Como vimos, as iniciativas de políticos como Nilo Peçanha, antes desse processo paulatino de diversificação da década de1930, já atuavam no intuito de diversificar para mudar. Na década de 1920, Nova Iguaçu já despontava como grande produtora nacional de laranjas. 


\section{artigos | e}

\section{E os Pomos eram de Ouro: A importância da Citricultura de Nova Iguaçu para}

a economia fluminense e brasileira nas décadas de 1920 à de 1940

A agricultura foi um dos setores que sofreu maior mudança, dentro dessa nova esfera da economia nacional. Não obstante, a laranja seguiu como uma alternância ao café, encontrando terreno para crescimento, principalmente em áreas como o grande município da Baixada Fluminense: Nova Iguaçu. Por sua vez, a cidade apresentará um crescimento econômico vertiginoso, além de uma grande migração de mão de obra para o trabalho nessa nova riqueza, que por sua vez, não brotava da terra como ouro, mais que dava frutos da cor do tão almejado metal.

Nisso, podemos também salientar que algumas políticas e incentivos para que os frutos cítricos pudessem se manter competitivos nos mais exigentes mercados externo foram feitas. Buscando-se a excelência na qualidade dos frutos e a ampliação dos mercados, são criados barracões especiais de beneficiamento, os Packing Houses. Essas instalações possuíam uma dinâmica produtiva diferenciada e fariam um turbilhão de mudanças na orientação do cultivo citrícola de Nova Iguaçu. Nisso, essas instalações também entram no processo modernizante que a agricultura passara no período dos anos 1930, nos quais a modernização da produção era ampliada por meios estatais ou privados, com o intuito de alavancar o país economicamente, trazendo tecnologias para aumentar a qualidade do produto final e levar a produção brasileira para um patamar mais tecnicista.

\section{Fontes}

\section{Anuário Estatístico do IBGE- Anos de 1936 e 1941}

Disponível em http://biblioteca.ibge.gov.br/biblioteca-catalogo?view=detalhes\&id=720. Acesso em 21/02/2015 às 14:00.

\section{Decretos-Lei}

Decreto $n^{\circ} 5.760$ de 24 de junho de 1930. Disponível em http://www2.camara.leg.br/legin/fed/decret/1930 1939/decreto-5760-24-junho-1930-561362publicacaooriginal-84976-pl.html. Acesso em 27/04/2015 às 09:34.

Decreto $\mathrm{n}^{\circ}$ 22.416, de 30 de Janeiro de 1933. Disponível em http://www2.camara.leg.br/legin/fed/decret/1930-1939/decreto-22416-30-janeiro-1933504172-norma-pe.html. Acesso em 27/04/2014 às 15:30. 


\section{artigos}

Ricardo Luiz Souza

\section{Diários Oficiais da União}

Disponíveis em: http://www.jusbrasil.com.br/diarios/DOU/1933/04/27. Acesso em 04/05/2015 às 14:56.

Livros impressos disponíveis no setor de obras raras da Biblioteca Nacional do Rio de Janeiro

AGRICULTURA, Ministério da. A Fructicultura no Brasil: Sua situação atual e o seu futuro. Rio de Janeiro: Tipografia do Ministério da Agricultura, 1932.

FRANÇA, Francisco F. Conselhos práticos para a cultura de laranjeiras. Granja Aparecida, Retiro Nova Iguassú. Rio de Janeiro, 1936.

Jornais acessados em www.memoria.bn.com

A Batalha (RJ), 30 de agosto de 1939, p. 04.

Correio da Manhã (RJ), 17 de maio de 1930. p. 08

Diário Carioca (RJ), 19 de junho de 1928, p. 07.

Diário Carioca (RJ), 30 de agosto de 1939, p. 08.

Diário Carioca (RJ). Quinta feira, 19 de junho de 1928, p. 07.

Jornal do Brasil (RJ), 19 de janeiro de 1929, p. 05.

Jornal Correio da Lavoura

Jornal Correio da Lavoura, 04 de Março de 1937, p. 1. Disponível no Centro de Documentação e Memória (CEDIM), situado na Universidade Federal Rural do Rio de Janeiro (Campus Nova Iguaçu)

Efemérides do Jornalista Sylvino de Azevedo (Disponível no Centro de Documentação e Memória (CEDIM), situado na Universidade Federal Rural do Rio de Janeiro, Campus Nova Iguaçu).

Efeméride do dia 23 de junho de 1929.

Efeméride do dia 24 de junho de 1933. 


\section{artigos | e}

E os Pomos eram de Ouro: A importância da Citricultura de Nova Iguaçu para a economia fluminense e brasileira nas décadas de 1920 à de 1940

\section{Referências bibliográficas}

CARVALHO, I. B. As Laranjas Brasileiras. Nova Iguaçu: Marvic, 1999.

DEAN, W. A Industrialização durante a República Velha. (org.) História Geral da Civilização Brasileira. O Brasil Republicano III. [5ª edição]. Rio de Janeiro: Bertrand, 1989.

DIAS, A. Entre laranjas e letras: processos de escolarização no distrito-sede de Nova Iguaçu (1916-1950). Rio de Janeiro, UFF, Tese de Doutorado, 2012.

FAUSTO, B. Expansão do café e política cafeeira. (org.) História Geral da Civilização Brasileira. O Brasil Republicano III. [5ª edição]. Rio de Janeiro: Bertrand, 1989.

FERREIRA, M. M. Em busca da idade do ouro. As elites políticas fluminenses na Primeira República (1889-1930). Rio de janeiro: Editora UFRJ, 1994.

FERREIRA, M. M.; PINTO, S. C. S. A crise dos anos 1920 e a Revolução de 1930. In: FERREIRA, J.; DELGADO, L. A. N. (Orgs.). O tempo do liberalismo excludente: da Proclamação da República à Revolução de 1930. “O Brasil Republicano”, v.1. Rio de Janeiro: Civilização Brasileira, 2003, pp. 387-415

FURTADO, C. Formação Econômica do Brasil. [34a edição]. São Paulo: Companhia das Letras, 2007.

HASSE, G. A Laranja no Brasil 1500-1987: a História da agroindústria cítrica brasileira. Dos Quintais colônias às fabricas exportadoras de suco do século XX. São Paulo: Duprat \& Propaganda, 1987.

HOBSBAWM, E. A Era dos Impérios. Rio de Janeiro: Paz e Terra, 2005.

LAMARÃO, S. T. N. Crise econômica e centralização política: o Estado do Rio nos primeiros anos da Era Vargas (1930-1937). Revista de História Econômica \& Economia Regional Aplicada - Vol. 5 No 8 Jan-Jun 2010

LEAL, P. F. Construção do Agricultor 'Orgânico': Os Sitiantes do Rio do Prata, município do Rio de Janeiro. Rio de Janeiro: Raízes, v. 30, n², jul-dez/2010.

LINHARES, M. Y. História Geral do Brasil. Rio de Janeiro: Campus, 1990.

LOBO, E. M. L. A Imigração portuguesa e a mão-de-obra do Rio de Janeiro na Primeira Republica. pp.287-319. In SILVA, S.; SZMRECSÁNYI, T. (Orgs.) História econômica da Primeira República. São Paulo: Edusp/Hucitec, 2002.

MARQUES, A. S. Baixada Fluminense: da conceituação às problemáticas sociais contemporâneas. Revista Pilares da história - Duque de Caxias e Baixada Fluminense. Ano 4número 6 abril /2006.

MELO, H. P. O café e a economia fluminense, 1889/1920. In: SILVA, S.; SZMRECSÁNYI, T. (Orgs.) História econômica da Primeira República. São Paulo: Edusp/Hucitec, 2002, pp. 215-234 


\section{artigos $\mid e$}

Ricardo Luiz Souza

MENDONÇA, S. R. Estado e economia no período 1930-1955. In: Estado e economia no Brasil: opções de desenvolvimento. 2a Ed. Rio de Janeiro: Graal, 1987

- Grande propriedade, grandes proprietários: Velhas questões, novas abordagens (18901930). In: SILVA, S.; SZMRECSÁNYI, T. (Orgs.) História econômica da Primeira República. São Paulo: Edusp/Hucitec, 2002.

Sociedade Civil, Sociedade Política e Agricultura no Brasil (1910 - 1945). História e Perspectivas, Uberlândia (48): 43-80, jan./jun. 2013.

NASCIMENTO, A. P. Trajetórias de duas famílias negras no pós abolição (Nova Iguaçu, século XX). In: VI Encontro Escravidão e Liberdade no Brasil Meridional, 2013, Florianópolis. Anais do VI Encontro Escravidão e Liberdade no Brasil Meridional. Florianópolis, 2013. v. 1.

OLIVEIRA, F. A Emergência do modo de produção de Mercadorias: Uma interpretação teórica da Economia Velha no Brasil. In: (Org.) História Geral da Civilização Brasileira. O Brasil Republicano III. [5ª edição] Rio de Janeiro: Bertrand, 1989.

OLIVEIRA, O.; ROBERTS, B. Las estructuras agrarias de América Latina, 1930-1990. pp. 216-267. In: BETHELL, L. História da América Latina: A América Latina após 1930: Economia e Sociedade Vol. 6. São Paulo: EdUSP, 2005.

PEREIRA, W. Cana, Café e Laranja: historia econômica de Nova Iguaçu. Rio de Janeiro: Fundação Getulio Vargas/SEEC, 1977.

POHL, E. M.; WILCKEN, A.; DUPRÉ, A. A. Bayer Belford Roxo 50 anos: 1958-2008: sua história, sua gente, sua cidade. São Paulo: Carrenho Editorial, 2008

POLANYI, K. A grande transformação. Rio de Janeiro: Leya, 2013.

PRADO JÚNIOR, C. História econômica do Brasil. São Paulo: Brasiliense, 2004.

RODRIGUES, A. O. De Maxambomba a Nova Iguaçu (1833 - 90's): Economia e Território em Processo. Rio de Janeiro, UFRJ-IPPUR, Dissertação de Mestrado em Planejamento Urbano e Regional, 2006.

SAES, G. A. M. O Nacionalismo Econômico e o Desenvolvimentismo do Tenente Juarez Távora (1930-1934). II Conferência Internacional em História Econômica \& V Encontro de Pósgraduação em História Econômica. Brasília, 23 e 24 de setembro de 2010.

SIMÕES, M. R. Ambiente e Sociedade na Baixada Fluminense. Mesquita: Editora Entorno, 2011.

SINGER, P. O Brasil no contexto do capitalismo internacional. (Org.). História Geral da Civilização Brasileira. O Brasil Republicano III. [5ª edição] Rio de Janeiro: Bertrand, 1989.

SOUZA, S. M. Da laranja ao lote: transformações sociais em Nova Iguaçu. Rio de Janeiro: PPGAS-MN, UFRJ, Dissertação de mestrado, 1992.

TEUTEBERG, H. J.; FLANDRIN, J. L. Transformações do Consumo Alimentar. In: FLANDRIN, J. L.; MONTANARI, M. (Orgs.). História da Alimentação. São Paulo: Estação Liberdade, 1998. 